\title{
SOCIO-CULTURAL VARIABLES AND MEDIA COVERAGE OF GIRL CHILD MARRIAGES
}

\author{
Godswill Okiyi, Ph.D \\ Department of Mass Communication, \\ Nasarawa State University, \\ Keffi, Nasarawa State \\ okiyigodswill@ hotmail.com \\ 08033025889,08155958716 \\ Chinwe Odionye, Ph.D \\ Department of Mass Communication, \\ University of Nigeria, \\ Nsukka, Enugu State \\ odionyechinwe@yahoo.com \\ 08065832040,08036515665 \\ Adenike Okeya, Ph.D \\ Department of Communication and Media Studies \\ Ajayi Crowther University, \\ Oyo, Oyo State \\ omotayookeya@gmail.com \\ 08038851146
}

\begin{abstract}
Girl-child marriages have been an ongoing practice in many traditional and modern societies. It is a common practice which exists in Asia, Africa, Europe and the Americas. Presently, girl child marriages predominate in developing countries, most of which have not accepted or domesticated the Child Rights Acts which aims to legalize the protection of children from different kinds of abuses. The media are expected to play roles of advocacy by setting agenda on such issues as child marriages by providing adequate coverage through news reports, editorials, interviews, features and other kinds of contents. This paper is a systematic critical analysis which relied on secondary data to examine issues explored. The study is underpinned by the mutedgroup and spiral of silence theories. While the latter examined communication patterns and social representation of non-dominant cultural groups like women and other minorities, the spiral of silence theory posits that the mass media work simultaneously with majority public opinion to silence minority beliefs or cultural issues. Literature revealed that the media do not significantly report social problems of child abuse and violence. Reportage of other sections of societies occupies more prominent media space. However, as part of roles of the media, they are to sensitize and create awareness of issues related to rights and protection of children.
\end{abstract}

Keywords: Socio-Cultural, Media Coverage, Girl Child, Marriages

\section{INTRODUCTION}

The girl child in the history of mankind has always been at the receiving end of social injustices perpetrated. These are manifested in different forms, including forced labour, sexual violence, rape, slavery, child prostitution, inadequate or lack of education, and forced early marriage. Elaborating on this, Thomas-Odia (2018) observed that there are about " 100 million Nigerians who are currently living below poverty level. They account for over 61 percent of our population represented by the countless numbers of women who are unemployed, have no access to healthcare, and the girl child who is denied basic education." By implication therefore, most social ills are borne by women, who include girl children. 
A look at issues of insecurity also reveal that the girl child is most vulnerable than other groups in the Country. For example, from April $14^{\text {th }}$ to $16^{\text {th }} 2014$ about 270 young college girls were abducted by the terrorist group Boko Haram, in Chibok, and till now, a large number of them cannot be accounted for. According to the United Nations High Commissioner for Refugees, around $80 \%$ of refugees are women and children. Mass rape has been extensively documented in recent civil conflicts and has been used systematically as an instrumentof torture or ethnic domination. A common denominator is that it is girls and women who are victims of such violence. And in some cases, they are bound socially and culturally by traditions and beliefs to acquiesce or submit to what is demanded for by their parents, guardians or abductors, as may be the case. This was emphasized by Igube (2004) when she observes that, "women live in a world determined by culture and tradition which restricts them to the home. Women are thus disadvantaged, vulnerable with respect to taking advantage of economic opportunities." She further pointed out that "early marriages and obnoxious widowhood rites keep girls out of school, contribute to female vulnerability and poverty.' According to Nworgu \& Shebbs (2016), "the girl child is regarded as a liability to the family in some places and at other times maltreated, denied access to education, denied proper health attention, subjected to 'slavery' in the guise of home training and above all forced into marriage against her will."

A UNICEF Africa advocacy advertisement stated that 125 million girls are married before 18 in Africa. This statement reveals the extent to which the culture of girl child marriage has been accepted across the continent, and steeped in traditions, cultures and religions which define the different nations, ethnic groups and peoples of Africa. Demographically, girl child marriages occur mainly in poorer geographies of society, especially in rural communities where standards of living is low. This is because girls are seen as options which can be traded off to richer men to ease their families' financial difficulties, and this is accepted by communities and societies they live in. As Okoye (2016) observes, "girls stand the risk of being given out as house helps, being given out in early marriage, being abused both physically and otherwise, and often at the risk of premature death".

While socio-economic factors determine parents/guardians acceptance or submission to society's allowance for girl child marriages, religious and traditional factors also play significant roles. Besides, members of middle-upper class of societies, engage in girl child marriages. For instance, Ahmed Sani Yerima, a former governor of Zamfara state who also served as a senator of the Federal Republic of Nigeria was alleged to have married a 13 year old Egyptian girl. Ironically, this took place, after the Child Rights Act was signed into law in the Country in 2003. According to him, "I do not work with such laws that run counter to my religion. For clarity, I do not have to obey the Child Rights Act so long as it contravenes my religious belief...". Another story that trended recently on social media was that of a Sudanese child bride, Noura Hussein (16 years at the time of marriage) who killed her husband on May 3 2017, as a result of rape and violence against her. The legal age for marriage in Sudan is 10 years, and there are no statutory laws which protect women from rape, as it is not considered a crime. These instances reveal dominance of religious precepts and beliefs over statutes which a nation's Constitution provides for. These are institutional influences through which long held attitudes and beliefs can be modified, and changed for new thinking and ideas.

The media are those channels through which newsworthy information are transmitted to a widely spread heterogeneous audience members who have the means to receive and interpret the contents. There is also the Internet which has further broadened the availability 
channels through which individuals and groups can reach each other, and on which virtual communities are built. Through the Internet, social media applications such as Facebook, Twitter, Whatsapp and others have been created and popularized. Popularity, availability and interactive abilities of social media have further made them veritable means through which campaigns are carried out, amplified and sent across millions of individuals who exist virtually oncyber sphere. Bearing in mind the functions, roles and availability of different media types, it is presumed that they will engage in public interest campaigns against practices like, girl child marriages.

The media are expected to play significant roles of advocacy by setting agenda on the issue through news reports, editorials, interviews and features meant to generate discourse that will impact through implementation of legislations, policies and regulations put in place to stop such practices. As Lasswell (1945) observes in Okiyi (2016), "societies require communication in order to learn what is going on around them, to enable different parts of the society to keep in touch with each other and coordinate their activities and to pass on their cultural heritage from one generation to another." It is the function of the media to sensitize the public of the need to change the practice of child marriage which has deleterious consequences on society.

\section{CONCEPTUAL DISCOURSE OF KEY TERMS}

Various terms are considered key throughout this paper. These include the following:

\section{Cultural impediments}

In every society there are norms, values, ideas, thinking and mores which more or less define what that society is all about. These values are also used as forms of identification by others for the generality of the other people. According to Ihechu, Okugo, Amah \& Afulike (2017), "culture is the characteristics of a particular group of people defined by everything from language, religion, cuisine, social habits, music and arts". It deals with the essence of existence within a particular milieu of the human being in a given society. Citing Schreek (2000), Ihechu, et al noted that culture is that complex whole which includes knowledge, beliefs, arts, morals, law, custom and other capabilities acquired by man as a member of society cultural practices against women.

To Famade (2016), culture is defined as, "a way of life of a group of people, the behaviours, beliefs, values and symbols they accept, generally without thinking about them, and that are passed along by communication and imitation from one generation to the next." To change attitudes formed as a result of such cultures, education and new information, especially through the media, can bring about such transformation. As Ihechu, et al (2017) further observed, "culture of patriarchy has eaten deep into the fabrics of the Nigerian and African societies. Male dominance and cultural arrogation of 'powers', 'rights,' and 'privileges' in matters affecting both males and females, are the order of the day." It is accepted as Nigerian culture and tradition or customs. Finally Nwaolikpe (2018) observes, "Child marriage is a product of cultures that devalues women and girls and discriminates against them."

An impediment is a hindrance or an obstruction which stops one from doing what otherwise he or she would have done. It is also related to the lack of progress. By implication when societal issues are not given the attention expected, it draws back, reduces progress and retrogresses rather than move towards the achievement of a goal, a cause and other factors pertinent to development in society. Cultural impediments therefore are those values, practices and attitudes which ensure that pursuit of ideals which shall enhance development 
in a society are hindered. For instance, whereby institutions of society such as the media are not used to foster growth as a consequence of cultures, the latter (cultures) become impediments.

\section{Girl child marriage}

Concept of the girl child marriage or early girl child marriage is topical, and a well-known travesty in different societies. It is a practice that has existed with man and as a result of traditional and cultural variables, is not given much attention or prominence, except in such situations when a notable figure like Senator Ahmed Sani Yerima is involved or some other spectacular consequence arising from such a union.

The Convention on the Rights of the Child (1989) considers all individuals who are below the age of 18 as children, and the generic title, 'children' is used for them. The girl child is defined as a young woman. Etymologically, it is a female human from birth, to adolescent to adulthood, when she becomes a full-grown woman. According to CDC, $9-11$ years, is a period of middle childhood ages, a period when the child tries to wear more complex looks, make friendships and share emotional attachments. Nwaolikpe (2018) says that, "child marriage as a global issue involves the giving out to marriage a child who is not mentally, psychologically, emotionally or physically prepared for a marital life to an older man who most times has children same age as the girl bride."

There are some sociological reasons which are drivers of early child marriage these include poverty, poor educational attainment, and strong social and religious factors. These factors determine what happens to the girl child, and her place in the rungs of society. UNICEF rates child marriages highest in sub-Saharan Africa across the Globe; around 4 in 10 girls marry before age 18. West and Central Africa have the highest percentage (42\%) of women aged 20 to 24 years who were first married or in union before age 15 and after age 15, but before age 18. Child marriage in Nigeria is centred on religious and cultural norms. Citing Fayokun, Nwaolikpe (2018) observes that, "it is believed that early marriage for a girl child maximizes her childbearing potentials."

Offshoots of girl child marriage are enormous and have debilitating effects on society at large. Okafor (2016) citing UNFA (2012) observes that early and forced marriage remains a key issue and important factor limiting young women's engagement in both education and economic activities. According to Nworgu and Shebbs (2016), "the girl child is regarded as a liability to the family in some places and at other times maltreated, denied access to education, denied proper health attention, subjected to slavery in the name of home training and above all forced into marriage against her wish, mostly, at early age of life."

To Ihechu, et al (2017), "the moment a girl child is born in Nigeria, she starts to encounter discrimination. People who come to felicitate often greet the birth of a girl with less glee than that of a boy. Some people even respond to questions on the sex of a new baby girl by saying she is another 'asewo' (prostitute), especially if the mother had given birth too many female children in the past." The manifest expression of discrimination against the girl child in society therefore includes considerations given to her as an inferior being who can be traded off like chattel, or married off against her will to provide financial gain or some form of friendship, alliance or support for her immediate family.

\section{Mass media and gender issues}

According to Asadu (2007) in Goodluck and Ojo (2014) the mass media refer to all avenues through which information can be passed from one person to numerous scattered 
heterogeneous audiences. They are also vehicles through which messages, information, ideas, knowledge and culture are transferred from one person to the other. Continuing, Nwachukwu and Okiyi (2014) observe that, "mass media forms and others have significant impact on the society as channels of message conveyance to the modern society at large in a variety of ways.The mass media play pivotal roles as they bring issues to the public sphere, which impacts society, affect public opinion and define how audience members see or respond to topical issues that happen around them, and invariably affect them.

They are channels which over time keeps changing and defining societies till the present. Through the media injustice and man's inhumanity to man are exposed, and offenders punished. Such are public interest roles which the media play when they serve as watchdogs of society, and ensure orderliness in the society for the common good. The media are expected to significantly play roles which examine place and proper representation of women in society through contents of their presentation and messages passed across. As McQuail (2010) observed, "the question of gender touches almost every aspect of the media-culture relationship" (p. 121). A notable observation is in the selection and production of news which is male dominated, and which covers less female subjects or news.

Mass media channels have impacted society in several ways. According to Obasi (2003), "as agents of socialization they have induced and will induce a great deal of positive behavioural and attitudinal change among the people of Nigeria. Through information, they increase the people's awareness; and by their educational role, they fight backward practices and beliefs and help the people to appreciate and adopt new ways." Stressing this, Ibraheem (2014) observes that, "the mass media are responsible for the circulation of particular ideas and images, and insofar as these shape thoughts and actions, the mass media are thought to wield discursive or ideological powers" (p. 413). Citing Schlesinger (1978), he notes that what really influences the content is the performance of the journalist as an impartial umpire ... journalists define reality in terms of what they perceive legitimate or acceptable interests in the society.

As Uzochukwu, Morah and Okafor (2015) observe, "media coverage of the abuse and neglect of children perform an important and significant role in placing issues such as child abuse on the public and political agenda" (p. 284). Citing Lindsey (1994), they further observed that media has a central role in mediating information and forming public opinion. The media casts an eye on events that few of us directly experience and render remote happenings observable and meaningful (p. 285). Mass media channels and journalists therefore determine how discourses of national interests are shaped, and through them attitudes and behaviour can get changed through information provided.

\section{THEORETICAL FOUNDATION}

Theories on which the work is underpinned are: muted group and spiral of silence theories. A major proponent of the muted group theory is Cheris Kramavae (1974). It is a feminist and cross-cultural theory which explains communication patterns and social representation of non-dominant cultural groups like women and other minorities. It recognizes that customs, norms and values tend to favour men more than women. As Asemah, Nwamuo and NkamUwaoma (2017) observe, "every custom, norm, value, etc. in all societies, tend to be to the advantage of the men and to the disadvantage of the women and other subordinate groups" (p. 253). Mutedness occurs as a result of lack of power, and people with little power do not often voice their perceptions, and when they do, they are muffled and invisible. Most media organizations are dominated by men, and this affects the ways in which women's issues are 
reported, or framed in the first place. This further confirms Igube's (2004) assertion that, "the print media in Nigeria has not been women friendly. Women issues rarely if ever, get front line coverage in the national dailies. The Nigerian media tend to be hostile to women and their issues." (p. 179). According to proponents of the theory, manmade language aids in defining, depreciating and excluding women, thereby making them a 'muted' group. Asemah, et al (2017) asserts that, "men are the gatekeepers of communication and this is because men attend to and treat as significant only what men say." (p. 255) In relation to this, Igube (2004) observes that, "the Nigerian media characterizes women as sex objects, passive, frivolous people." The muted group theory is considered appropriate for this work as issues of girl child marriage are not given prominence as a result of the media being male dominated.

The spiral of silence theory was propounded by Noelle Neumann in 1984. It posits that the mass media work simultaneously with the majority public opinion to silence minority beliefs or cultural issues. Fears of isolation make those with minority views to examine the beliefs of others. Those who fear to be socially isolated are likely to conform to what they perceive to be the majority view.

According to Asemah, et al, (2017), "the theory says that ... the media create opinions and that ideas, occurrences and persons exist in public awareness partially, only if they are lent sufficient publicity by the mass media, and only in the shapes the media ascribe to them" ( $\mathrm{p}$. 89). By implication, as media are male dominated, the fear of holding opinions which negate the belief system or cultures which are popular with such media will push such persons and their views into spirals of silence, and from which they may not be heard. As such reports of girl child marriages may not be heard, given that such views go against those of majority of the people. People are unwilling to express their opinions if they fall within the minority purview. The more marginalized one is, the less likely he will speak out, and will spiral into a fully marginalized position.

The implication of the spiral of silence theory is pertinent here as it reflects on a group which is considered subordinate (females) and are pushed to silence as a result of the dominance of male positive media types which is seen in media organizations, structures and in news contents. Appropriateness of the spiral of silence of theory is on principles guiding relationship between social problems like girl child marriage to impact of culture and religion, and a male dominated media system in lack of prominence it requires.

\section{OVERVIEW OF CHILDREN'S RIGHTS}

Human rights are as old as society itself as they derive their existence from the need of humans to live, develop and achieve their destinies in life. The Universal Declaration of Human Rights which constitutes the most comprehensive and central document on human rights was adopted on the $16^{\text {th }}$ of December 1948 by the General Assembly of the United Nations. Children's rights are part of human rights and are embedded in the Human Rights Declaration. Nwodu \& Ezeoke (2013) summed up ratifications and adoption of the rights of the child by the United Nations at its General Assembly of 20 November 1989, to include but not limited to: freedom of expression, thought, conscience and religious association, privacy, access to appropriate information, parental responsibility; protection from abuses and neglect of child without a family, adoption, education, social security, standard living, protection from child labour, sexual exploitation and drug abuse, protection from sales, trafficking and abduction, and protection from torture and deprivation of liberty. 
Indeed, children's rights span a wide range and cover a lot of issues. A cursory look reveals that they are interrelated; however the right to protection from sexual exploitation is our focus. And by listing it, the UN gave it international recognition which calls for the protection of children from sexual abuse which early marriage encourages, as the girl child is forced to engage in sex without consent, an activity which is also illegal, since the practice is outlawed.

Attempts to safeguard rights of the child were described succinctly by Oyero (2009) when he observed that it began with the 1924 Geneva Declaration of the Rights of the Child, followed by the 1959 Declaration of the Rights of the Child and the declaration of 1979 as the International Year of the Child by the United Nations. There is also the United Nations Convention on the Rights of the Child which was adopted and ratified on November 20, 1989. Relevant articles of the Convention include the following;

\section{Article 34}

States Parties undertake to protect the child from all forms of sexual exploitation and sexual abuse. For these purposes, States Parties shall in particular take all appropriate national, bilateral and multilateral measures to prevent:

a) The inducement or coercion of a child to engage in any unlawful sexual activity;

b) The exploitative use of children in prostitution or unlawful sexual practices;

c) The exploitative use of children in pornographic performances and materials.

\section{Article 35}

States Parties shall take all appropriate national, bilateral and multilateral measures to prevent the abduction of, the sale of or traffic in children for any purpose or in any form.

\section{Article 36}

States Parties shall protect the child against all other forms of exploitation prejudicial to any aspects of the child's welfare.

Articles 34 - 36 above provide for the protection of rights of children against sexual abuse and misuse of children, abduction and sale of children which some cultures carry out when they forcefully marry girl children out, and the need to stop the exploitation of children. By implications Governments and individuals need to seek for promotion and protection of child rights. Article 13 of the Convention enshrined children's right to freedom of expression, while Article 17 called on the mass media to disseminate information and materials of social and cultural benefits to the child. The Organization of African Unity, OAU adopted a charter on the Rights and Welfare of the African Child. This charter was enacted taking into consideration the situation of the African Child which is at critical social, economic, cultural and developmental circumstances.

Drawing nearer home, the Children's Rights Act (2003) was enacted as a legal documentation, and protection of children's rights and responsibilities in Nigeria. This law incorporates the rights of the Convention on the Rights of the Child (CRC), and the African Charter on Human Rights into the national law; which are to provide responsibilities for government agencies associated with the law, and to integrate children focused legislations into one comprehensive law. Again, it acts as legislation against human trafficking as $j$ forbids children from being separated from their parents against their will except where $i$ 
in the best interests of the child. Several states in Nigeria have adopted the Child Rights Act, and by their assent, such states believe that its' reenactment and passage will bring respite to the Nigerian child from parents, guardians and other erring relatives.

The issue of forced marriage, especially by abduction is treated under Section 272 of the Penal Code; abduction is akin to kidnapping whereby the victim is lured away by deception or trick. The offence is punishable by 10 years imprisonment under Section 273 Penal Code. And under Section 361 of the Criminal Code, any person who with intent to marry or carnally know or cause her to be married or be carnally known by any means, detain her against her will is guilty of felony, and is liable to 7 years imprisonment. Further, any person who unlawfully takes an unmarried girl under 16 years out of her parents' custody or against her guardians will is guilty of a misdemeanor and is liable for 2 years imprisonment. This addresses the issue of forced marriages and abduction of women as sex slaves. Also, defilement of a girl under the age of 13 years attracts life imprisonment; while an attempt to have carnal knowledge of such a girl attracts 14 years imprisonment. A girl above 13, but under 16 or knowing a girl who is an idiot or an imbecile or attempts to have unlawful carnal knowledge of her, will be guilty of felony, and liable to imprisonment for 2 years.

These are some penalties created to serve as deterrence to sexual offences against women and girl children. Despite these legislations, different kinds of child abuse happen daily in Nigeria. Among these are girl child marriages which take place between children from tender ages of 8 to 14 to older men. These illegal marital contracts are forbidden by legislations enacted by national and states assemblies in the country. Some of the reasons adduced for its continuation are cultural inhibitions and religious dictates, while the media do not provide adequate coverage of such incidents.

\section{Hindrances to reporting on girl child marriage in Nigeria Underreporting of girl child issues by the media}

This relates to issues of male dominance and influence of religion by the media that leads to underreporting of girl child marriages. The danger with this constraint is the multiplier effect it has not only on the media, journalists but also on likely target consumers of the news who could be interested in it. As Nwaolikpe (2018) observes in her study that there has not been enough focus on child marriage in Nigeria, and when covered, some of the news stories did not explain in details implications and consequences of child marriages to the Nigerian girl.

Despite statistics, the mass media have not really covered the issue of child marriage adequately despite its significance in the country and region. Further, Ihechu, et al (2017) in their study on media coverage and framing of cultural practices that target women, observe that there is, "insignificant coverage of cultural practices that denigrate women," while the framing pattern exhibits a non-condemnatory stance. They further pointed out that some major factors responsible for these include: low awareness and knowledge among journalists/reporters, culture of patriarchy, and lack of sponsorship.

Nwodu and Ezeoke (2013) confirmed the findings above on dominant women and children rights issues which include protection rights of women and children with disabilities, abuse and violence against women, and harmful practices such as child marriage, female genital cutting, and exploitation of women and children received 19.3\% media attention. And in their three-month study of broadcast media (FRCN and AIT) coverage of issues of early child marriage received only $10 \%$ coverage within the period. They concluded that constraints to media coverage of such issues include low awareness and knowledge among journalists $y$ 
84\%. Besides these, some studies revealed apathy by journalists on women and children issues. And when they do cover such, framing, story direction and the style of coverage deemphasizes their importance, and affect consumers of such news.

Recent cases of gender-based violence, killing and rape of young girls and women have been reported nationally, including the sensational case of Uwaila Vera Omozuwa who was attacked and raped in a church, but died a few days after in Benin, the capital town of Edo state. Another college student Barakat Bello was raped and killed during a robbery attack in her home in Ibadan. These cases received wide coverage from popular national and private TV stations. However social media were used effectively by individuals and international NGOs like Amnesty International to complement, amplify and relay the news across virtual communities. Through these information sharing activities, gender-violence and sexual offences against women and children have remained topical in national consciousness. In an online CNN report, President Buhari reiterated his government's commitment to fighting gender-based violence. According to him, "I am particularly upset at recent incidents of rape, especially of very young girls. The police are pursuing these cases to bringing perpetrators of these heinous crimes to swift justice." It can be deduced that complementing conventional and online media coverage of gender-based violence and rape provide the impetus needed to give adequate reportage to such crimes.

\section{Cultural influences}

Societal and cultural factors such as media ownership structure, cultures, religion and male domination of the media account for the under-reporting of girl child marriage as a crime. These factors are interdependent and intertwoven. Media are institutional organs which exist and are influenced by society, and in their own ways, influence and determine how society is perceived. As such, these factors, especially, religion and culture override how certain issues, may be reported or even perceived. Like Okoye (2016) observes, "even where the Constitution and national laws uphold gender equality, religion and cultural gender ideologies dominate in practice and have been used to express the notion that there can be no equality, as men and women are different from creation."

These two dominant values of religion and culture wield influences on other aspects of society, which explains why pertinent issues may not receive the attention they deserve. Consequently, the media are influenced to underreport, frame or position some news items in ways that conform with societal expectations. According to Nwodu and Ezeoke (2013), "as both social institutions and business concerns, the mass media constitute an indispensible arm of human society; in this context, what the media choose to emphasize or ignore, affect how people perceive or understand the issues" (p. 45). As such when the media ignore certain issues, there is the likelihood of the isolation of categories of people affected by the issue, and relevant members of the public who can influence and control such circumstances. To Okiyi, (2016), "without proper information, most people would be unaware, uninformed and would certainly be disinterested in the issue which is being propagated by the government or Agency" (p. 57).

Uzochukwu, et al (2015), citing the Asian Summit on Child Rights and the Media (1996), and the Oslo Workshop (1996) observe that, "part of the Summit's resolutions is that media content aimed at children should be of high quality, made specifically for children, should not exploit them but support their mental, social, moral and spiritual developments" (p. 280). The implication is that for the media to carry out their roles on issues which impact children, they should be as professional and ethical as can be, without undue influence. Uzochukwu, 
further provided guidelines which were suggested by journalists at the first International Consultative Conference on Journalism and Child Rights held at Recife, Brazil in 1998, and they state that:

All journalists and media professionals have a duty to maintain the highest ethical and
professional standards, should promote within the industry the widest possible dissemination
of information about the International Convention on the Rights of the Child and its
implications for the exercise of independent journalism. Media organizations should regard
violation of the rights of children and issues related to children's safety, privacy, security,
their education, health and social welfare and allforms of exploitation as important questions
for investigations and public debate. Journalistic activity which touches on the lives and
welfare of children, should always be carried out with appreciation of thevulnerable situation
of children.Journalists and media organizationsshall striveto maintain the highest standards
of ethical conduct in reporting children's affairs

Using these guidelines therefore, media houses and journalists are expected to uphold the rights of children as determined by the United Nations Convention on the Rights of the Child, and other charters that deal with similar rights. As Oyero (2009) pointed out, "the challenge to media professionals at all levels and in all media is to raise awareness in the media professions about the rights of children and how they can be protected and promoted by good professional practices or harmed through inappropriate policies or actions." The onus therefore lies with media houses and journalists to carry out such moral crusades with zeal, diligence, objectivity and fair-mindedness while covering children issues.

Different scholars (Nwaolikpe, 2018; Nwodu \& Ezeoke, 2013; Okoye, 2010, Uzochukwu, et al, 2015\& Oyero, 2009) revealed that the media do not report social problems of child abuse and violence which go against dictates of various conventions except, where such are scandals or sensational news items on child abuse; they do not dominate the media. The media do not adequately cover stories of children, their lives, their rights and protection against abuse, labour, mortality, neglect, trafficking, and prostitution and so on nor do they reveal information about sources of information, concerning these. On the other hand, Molism (2016) observes that media coverage of girl child has gone high. According to her, media coverage has shifted from focusing on the issue, to a narrative that looks at solution. However, this perspective may have arisen taking into cognizance that she wrote from a western point of view where gender issues are given prominent attention which is at variance with what obtains in Nigeria and other developing countries.

\section{Gendered dimension of the mass media}

One of the major hindrances to effective reportage of girl child marriages is the existence of media landscape that is still very much male dominated in Nigeria. This is achieved through ownership, management structure and newsroom gender composition. One of the highlights of the 12 Platforms for Change from the 1995 Beijing Conference is found in number 6 which states that, 'men dominate the mass media and through it propagate the negative stereotypes of women'. According to Igube (2004), "the print media in Nigeria has not been women friendly. Women issues rarely, if ever get front line coverage in the national dailies, the Nigerian media tends to be hostile to women and their issues" (p. 179). This was further confirmed by Ihechu, et al (2017) when they posit that cultural practices against women in Nigeria is an offshoot of the patriarchy that existed in pre-colonial Nigeria, where women occupied inferior positions in socially constructed scheme of things. The culture of patriarchy has eaten deep into the fabrics of the Nigerian and African societies. Such is acceptable within Nigerian cultures, traditions and customs and as a result there is a tendency to deprioritize issues such as cultural practices against women. From the above, we can deduce 
that male dominance is a major factor which can hinder prominent coverage of girl child marriages.

\section{Religious Influences}

Religion is a significant cultural factor that impacts heavily on how issues of girl child marriage are reported by the media. Most religions support categorization of females in secondary positions, and as a consequence they are subjugated and suppressed in different aspects of life. Religion is a belief in a supernatural Being who created all things, and to whom much devotion and worship is bestowed. It is also a sub-set of our cultural beliefs, as it determines our values, norms, and ways of life, beliefs and morality. As a result, religious dictates which may go against societal values, are rather obeyed than laws of the land. According to Igube (2004), "under Islamic injunction, the woman is viewed as weak, incapable of decision making" (p. 27).

This maxim is also true of Christianity which holds that the woman should submit to the man and respect him. Sins committed in some cases have sterner penalties for women than for men, especially sexual ones, divorcement. These have consequences for news reportage. Islam does not condemn marriage of girls, it may not be seen as a crime nor seem to hold much news value from a reporter who agrees with such religious views. According to Nwaolikpe (2018), child marriage in Nigeria is centred on religious and cultural norms. Citing Fayokun, she observes that it is believed that early marriage for a girl child maximizes her child bearing potentials. And as Ihechu, et al (2017) observe, "early marriage is practiced in different parts of Nigeria but more in the Northern parts of Nigeria (mostly among the Muslims). According to Bot and Kwaja (2015), Senator Yerima was accused of marrying an under aged Egyptian girl but the case was dropped because the Nigerian Constitution under Article 61, Second Schedule, the Nigerian Government cannot legislate on "marriages" under Islamic law (paraphrased). By implication, media coverage of issues related to girl child marriage may not give editorial consideration as a result of influence and perception of target consumers of the news media.

\section{Commercial and Political Interests above moral crusades}

Finally, there are altruistic reasons which may also have cultural offshoots, in the long run why news of early girl child marriages do not get the due attention they ought to, especially considering that they are criminal activities. However, media owners and editorial personnel also quantify news as to their worthiness, and influence on the potential receiver. According to Nwodu and Ezeoke (2013) the media is seen, "as both social institutions and business concerns, the mass media constitute an indispensible arm of human society. In this context, what the media choose to emphasize or ignore affect how people perceive or understand the issues." By implication, what society gets to know, are seen through the perception of the media and these are defined by factors which include interests of owners, advertisers, political and economic forces. These determine what is reported, given prominence and what is not. In Nigeria, political issues receive more attention than other important issues such as education, environment, oil and gas and so on. The media are selective over what news items to allow, and due to this, they emphasize political and economic issues rather than others like girl child marriage or related issues. Further, sponsorship of media content and advertising also de-prioritize social issues like early girl child marriages. Prominent spaces in newspapers/magazines and prime time on radio/TV are used for more popular themes and for commercial purposes for the profitability of stations and newspaper houses. And through sponsorship, objectivity is affected. 


\section{CONCLUSION}

This paper examined socio-cultural impediments which hinder reporting of girl child marriages in developing countries.World over; there is recognition of the problem of girl child marriage, which is enacted in conventions and charters, internationally and nationally. However this social malaise does not receive the prominence it deserves due to socio-cultural influences. It was discovered that principles guiding muted group and spiral of silence theories are applicable to this study as women and girl child fell into marginalized groups with no voice of their own, especially in male-dominated political structures, and in most newsrooms. Issues that relate to females may not receive the significant coverage they deserve because of different underlying variables that will impact such news items. Further, the dominant majority who are concerned with news creation and transmission are men who determine editorial decisions, and through such, they influence themes that set agenda for the audience. Invariably, dissenting voices or coverage will not receive as much attention as popular views expressed, and over time will join the dominant voices to express related opinions.

Issues of girl child marriage are not only common to Nigeria, but prevail in most developing countries without strong legal and political structures. In India, Pakistan, Sudan, South Africa, Ghana, Bangladesh, Niger, Latin American nations and a host of other countries, girl child marriages predominate as a result of religious and socio-cultural practices. According to a UNICEF 2019 report, about 12 million girls are married before they turn 18, and in the developing world, one in nine girls is married before they turn 15 . Thus, more needs to be done to overcome the challenge of girl child marriage, rape and gender-based violence against women, which often takes other structural dimensions that needs to be studied.

To reduce or stop girl child marriages among other crimes committed against women, legislations enacted have to be made workable. That is, such Acts of parliament should be enabled to work against perpetrators of such violence. Concerned ministries including the ministry of Justice, Information, Education, Youth and Development, Women Affairs, Police Affairs and others should collaborate to produce a national roadmap or framework that will work to achieve goals of ensuring punishment of perpetrators, and carrying out campaigns against girl child marriages and other related actions. Roles of NGOs and the media cannot be overemphasized in such campaigns, with the intention to expose perpetrators and raise consciousness of Nigerians on ills of girl child marriage and effects on the society as a whole.

We can conclude with observations of the National Council of Women Society, NCWS (2014) in Ihechu, et al (2017) that:

The task of liberating the Nigerian woman and indeed the African woman from obnoxious, barbaric and outdated cultural practices is a collective one. It is an action that requires all and sundry and most importantly the media ... we need the media to tell our stories, our experiences and ordeals... that way, the society can feel our plight and that mark a big step towards ending ill-treatments against women in the name of culture

It is encouraging that there are frameworks to fight girl child marriage, however cultural and attitudinal changes are needed through constant education and adequate media coverage to achieve desired results. 


\section{REFERENCES}

Asemah, E. S, Nwammuo,A. N \& Nkwam-Uwaoma, A. O. A. (2017). Theories and Models of Communication, Jos: MATKOL Press.

Adebayo, B. (June 12, 2020). Nigerian state governors resolve to declare state of emergency on rape following spate of sexual violence, https://edition,conn.com, retrieved on July 19, 2020.

Bot, D. D. \& Kwaja, G. (2015). The Child Marriage Online Discourse by Young Women in Nigeria, (ed.) Wilson, D. Communication, Society and the Nigerian Child: Issues and Emerging Trends in the $21^{\text {st }}$ Century,(103 - 116), Uyo: BSM Resources Ltd.

Famade, O. A. (2016). Influence of Tradition and Cultural Belief of Parents on their WillingnessTo Finance Girl Child Education in Zamfara State, International Journal of the Forum for African Women, 4 (2), 42 - 52.

Goodluck, L. \& Olusola, M. O. (2014). Mass Media and Religious Conflicts in Nigeria: A CaseFor Social Responsibility, KSU Journal of Mass Communication, 3, 164 - 178.

https://www.bbc.com>news (10 May 2018). Noura Hussein: Sentenced to death in Sudan for killing 'rapist husband' retrieved on 8 March 2019.

https://www.nairaland.com (10 May 2010). Senator Ahmed Sani Yerima Justifies Marriage to 13 year old Egyptian Girl, retrieved on 8 March 2019.

Ibraheem, I. A. (2014). Media and Politics: A Study of Nigerian 2011 General Elections, (eds) Oso, L, Olatunji, R \& Owens-Ibie, N, Journalism and Media in Nigeria: Context, Issues and Practice, (410 - 427), Ontario: Canada University Press.

Igube, R. B. (2004). Women and Gender Studies, Abuja: Sir Kaif Ventures Nigeria Coy.

Ihechu, I, Okugo, C, Amah, F. \& Afulike, C. (2017). Media Coverage and Framing of Cultural Practices that Target Nigerian Women, Covenant Journal of Communication, $4(2), 55-75$.

McQuail, D. (2010). McQuail's Mass Communication Theory, London: SAGE Publications Ltd

Mohsin, M. (24 February 2016). How can the Media do its Part to End Child Marriage? retrieved from https://www.girlsnotbrides.org>child-marriage, on 11 March 2019.

Nwachukwu, I. \& Okiyi, G. (2014), Impact of Mass Media on Modern Society: A Review of the Four Theories of the Press, KSU Journal of Mass Communication, 3, 157 - 163

Nwaolikpe, N. O. (2018). Should we keep this Quiet? Print Media and Child Marriage in Nigeria, Globalmedia Journal, retrieved from www.globalmediajournal.com, on 11 March 2019. 
Volume 1 Number 2

Nwodu, L. C, \& Ezeoke, C. B. (2013). An Evaluation of Press Coverage of Children's and Women's Rights in Nigeria, Higher Education of Social Science, 4 (2), 41 - 51.

Nworgu, L. \& Shebbs, E. U. (2016). Issues on Women and National Development: the Role of Local Governments in the Development of the Girl Child, International Journal of the Forum of African Women Educationalists, 4 (2), 15 - 25.

Obasi, O.O. (2003). Media and Society: An Introduction to Sociology of Mass Communication, Owerri: CREMD Publishers.

Office of the United Nations High Commissioner for Human Rights (November, 1989)

United Nations Convention on the Rights of the Child, Geneva, Switzerland.

Okafor, E. C. (2016). Empowering Women towards Economic Participation for National Development in Nigeria: Issues and Prospects, International Journal of Forum for African Women Educationalists, 4 (2), 8 - 14.

Okiyi, G. O. (2016). Communications Management, Chibok Girls' Abduction and Baby Factories in Nigeria: A Nexus of Underdevelopment Metaphors, International Journal of Forum for African Women Educationalists, 4 (2), 53 - 63.

Okoye, C. O. (2016). Empathising with Women who are an Endangered Species, International Journal of the Forum for African Women Educationalists, 4 (2), 1 - 7.

Oyero, O. (2009). Children as 'invisible' and voiceless as ever in the Nigerian news media, Retrieved from http://www.mediawise.org.uk/displaypage.php?id=130, on $11 \mathrm{March}$ 2019.

Thomas-Odia, I. (17 November 2018). Arise Women Celebrates $10^{\text {th }}$ Anniversary, retrieved from https://guardian.ng>arise-women, on 26 February 2019.

Uzochukwu, C. E, Morah, N. D \& Okafor, G. E. (2015). Coverage of Child Rights and Protection Issues: Analysis of Selected Broadcast Media in Nigeria. The Nigerian Journal of Communication, 12 (1), 272 - 297. 